\title{
Comparison the effect of high flux and low flux dialyzer on quality of life in hemodialysis patients; a clinical trial
}

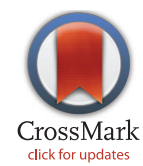

\author{
Khodayar Oshvandi ${ }^{1}{ }^{\oplus}$, Mehri Safari $^{2}$, Mahmood Gholyaf ${ }^{3}$, Abbas Moghim-Beygi ${ }^{4}$, Farshid Shamsaei ${ }^{{ }^{*}}{ }^{\circledR}$, \\ Mohammadreza Tamadon ${ }^{6}$, Neda Alimohammadi ${ }^{7}$ \\ ${ }^{1}$ Chronic Disease (Home Care) Research Center, Nursing and Midwifery School, Hamadan University of Medical Sciences, Hamadan, Iran \\ ${ }^{2}$ Nursing and Midwifery School, Hamadan University of Medical Sciences, Hamadan, Iran \\ ${ }^{3}$ Department of Nephrology, Shaheed Beheshti Hospital, Urology and Nephrology Research Center, Hamadan University of Medical \\ Sciences, Hamadan, Iran \\ ${ }^{4}$ Department of Biostatistics and Epidemiology, Modeling of Non communicable Diseases Research Center, School of Public Health, \\ Hamadan University of Medical Sciences, Hamadan, Iran \\ ${ }^{5}$ Mother and Child Care Research Center, Nursing and Midwifery School, Hamadan University of Medical Sciences, Hamadan, Iran \\ ${ }^{6}$ Department of Nephrology, Semnan University of Medical Sciences, Semnan, Iran \\ ${ }^{7}$ Department of Medical-Surgical Nursing, Instructor, School of Nursing and Midwifery, Hamadan University of Medical Sciences, \\ Hamadan, Iran
}

\section{A R T I C L E I N F O}

Article Type:

Original

\section{Article History:}

Received: 5 July 2018

Accepted: 6 October 2018

Published online: 7 November 2018

Keywords:

Dialysis

Quality of life

Hemodialysis

End-stage renal disease

Chronic kidney disease

Renal replacement therapy

High flux dialyzers

Low flux dialyzers

\begin{abstract}
A B S T R A C T
Introduction: End-stage renal disease (ESRD) is a worldwide public health problem. ESRD reduces health-related quality of life. Quality of life is an important determinant in the mortality and morbidity of hemodialysis patients. However, several studies have suggested that high flux dialyzers increase dialysis adequacy and reduce mortality and morbidity in these patients.

Objectives: This study aimed to investigate the effects of high flux and low flux dialyzers on the quality of life in hemodialysis patients.

Patients and Methods: In this clinical trial, 93 patients who met the inclusion criteria were randomly assigned to two groups of high flux and low flux dialyzers. Before intervention, both groups filled demographic and quality of life questionnaires. They were undergone dialysis with two dialyzers (one group by high flux and another by low flux) three times a week for 6 weeks. Then quality of life questionnaire was filled by both groups once again.

Results: The overall quality of life score was not significantly different in both groups before intervention $(P=0.121)$. After intervention, however, high flux group attained a significantly higher mean score $(54 \pm 10.4)$ than low flux group $(43.89 \pm 11.64)(P<0.001)$.

Conclusion: According to the results of this study, the use of high flux dialyzers can be a useful method to increase the quality of life in hemodialysis patients.
\end{abstract}

Implication for health policy/practice/research/medical education:

In a study on 93 hemodialysis patients ( 49 patients with low flux and 44 patients with high flux dialyzers), a significant difference of quality of life between the two groups was detected. High flux dialyzers can be a useful method to increase the quality of life in hemodialysis patients.

Please cite this paper as: Oshvandi K, Safari M, Gholyaf M, Moghim-Beygi A, Shamsaei F, Tamadon MR, et al. Comparison the effect of high flux and low flux dialyzer on quality of life in hemodialysis patients; a clinical trial. J Renal Inj Prev. 2019;8(2):98105. DOI: 10.15171/jrip.2019.19.

Introduction

End-stage renal disease (ESRD) is a crucial and serious disease defined as a progressive and irreversible impairment of renal function associated with the weakening of body's ability to maintain the balance of fluids and electrolytes eventually leading to uremia (1). The overall yearly incidence of the disease is reported to be
260 cases per million population with an annual increase of approximately $6 \%(2)$, and its prevalence continues to rise (3). In 2010, ESRD was recognized as one of the three causes of mortalities with a considerable increase from 1990 to 2010 (4). It is estimated that the proportion of people with ESRD will increase nearly $60 \%$ by 2020 in comparison with 2005 (5). In the United States, the 
mortality rate by ESRD is close to 85000 individuals (6). In Iran, the disease has a growing trend (7), while according to the studies, approximately 1200 to 1600 of people are annually diagnosed (8). Hence, it is very important to control and treat chronic kidney disease (CKD).

Patients with ESRD need to receive renal replacement therapy (RRT), including hemodialysis, peritoneal dialysis, or kidney transplantation (9) to survive. Each of these approaches has different effects on physical, psychological, and social health in these patients (10). Due to the dramatic increase in the need for RRT in recent decades and the upward trend and owing to the shortage of kidneys for transplantation and complications of peritoneal dialysis $(11,12)$, hemodialysis is the most common method of them (13). In 2014, the population of hemodialysis patients is estimated to be 2.662 million (14); This means that $89 \%$ of dialysis patients depend on hemodialysis (13).

During hemodialysis, blood leaves the body and its chemical composition is modified by the mechanisms of diffusion and ultrafiltration via passing through semi-permeable membranes to remove substances, and then returns to the body (15). Some types of dialyzers are available to be used by hemodialysis patients. The types of dialyzers are determined according to the patient's condition, desired results, and RRT. According to a classification by the national hemodialysis institute, dialyzers are divided into two categories of high flux and low flux dialyzers (16). One of the important aspects of hemodialysis treatment optimization is the development of dialysis membranes that remove a higher amount of larger molecules (17).

High flux dialyzer is made of cellulose membranes with a higher permeability compared to low flux dialyzers. The clearance of toxins with medium and high molecular weights, such as $\beta 2$-microglobulin, and phosphorus that accumulate during CKD, is higher in high flux dialyzers than in low flux $(17,18)$. According to the hydrophobic properties, high flux dialyzers absorb toxins associated with uremia and reduce cytokines and complement activators, thus, diminish inflammatory responses. It may also retard the long-term complications of hemodialysis (16). Due to inadequacy of low flux dialyzers in complete removal of uremic toxins, $90 \%$ of patients who are on dialysis show side effects on different body systems after a few years (18).

Special symptoms of high flux dialyzers include a considerable reduction in dialysis-related amyloidosis (18), reducing the risk of cardiovascular disease by removing homocysteine, declining the incidence of cerebrovascular disease (19), and improving the control of anemia (17). Some studies suggested that high flux dialyzers improve anemia associated with renal dysfunction and a reduce the need to inject human erythropoietin (EPO) compared to low flux dialyzers, which is probably due to the ability to repel particles with average molecular weights (20). The important role of dialyzer types to control of electrolytes such as hyperphosphatemia and its complications (17), and potassium removal during dialysis (21) can significantly affect the process of hemodialysis and its performance. Improvements in anemia and nutritional status enhance the quality of life and increase survival of patients. Therefore, strategies to control these issues, such as maintaining a suitable blood pressure, remaining kidney function, and ensuring the adequacy of dialysis can promote the quality of life in hemodialysis (22).

Various studies have specifically focused on the question whether the use of high flux dialyzers, compared with low flux dialyzers, might have measurable effects on survival of hemodialysis patients? Recent advantages in the use of high flux dialyzers have provided an opportunity for better clinical outcomes in these patients (23-25).

Despite progression in the treatment of ESRD patients, however, their quality of life is still an important issue (22). In fact, long-term complications of hemodialysis are one of the important factors affecting the quality of life in hemodialysis patients $(18,26)$. Quality of life is a pertinent concept in nursing practice and nurses are always trying to improve it.

Since chronic illness affects the whole life aspects of patients, physical, psychic and social conditions, nurses should obtain comprehensive information about the patients' quality of life (27). It has been demonstrated that the quality of life in hemodialysis patients is lower than normal peoples $(28,29)$, while patients have to cope with many disease symptoms such as physical problems, diet limitations, and changes in body image (10). The life expectancy will increase in hemodialysis patients owing to the removal of metabolism end products and excess water from the body. Strategies to control these issues, maintaining blood pressure, remaining kidney function, and ensuring the adequacy of dialysis can promote the quality of life (22). Evaluation of health-related quality of life can be effective on the examination of interventions' efficacy and increased involvement of patients in their care process (30).

One of the tasks of dialysis nurses is to be familiar with the dialysis process of patients and the implementation of interventions and protocols for enhancing the efficiency of dialysis to reduce complications, knowledge about the types of dialyzers and their advantages and also disadvantages. Additionally, the relation between dialyzer type and the incidence and severity of its side effects can help nurses to achieve their goals.

\section{Objectives}

This study aimed to compare the effects of high flux and low flux dialyzers on the quality of life in hemodialysis patients.

\section{Patients and Methods}

Study population and research design

This study was a clinical trial with participation of 93 hemodialysis patients referred to Shaheed Beheshti 
hospital, in Hamadan (2014). After obtaining informed consents, the sample was selected and randomly assigned to high flux or low flux groups. The inclusion criteria of the study were ages over 18 years, fistula or graft for hemodialysis, a minimum of three months of hemodialysis, at least three to four hours dialysis sessions per week, and lack of acute cardiac or pulmonary disease. The exclusion criteria included withdrawal of a patient to participate in the study, incidence of severe cardiovascular disorders, severe pulmonary disease, received blood transfusion during the study, recorded and known cases of moderate or severe depressions, loss of consciousness, irritability, agitation of the patient, discontinued dialysis for any reason, kidney transplant, acute infection, death of relatives, and the loss of jobs.

The sample size was 50 patients for each group, which calculated according to the study by Rahimi et al with a confidence interval of $95 \%$ and a test power of $80 \%$ and using the following formula;

$$
n=\frac{\sigma^{2}\left(z_{1-\frac{\alpha}{2}}+z_{1-\beta}\right)^{2}}{\left(\mu_{1}-\mu_{2}\right)^{2}}
$$

In this study, one person was excluded from the low flux group $(n=49)$ because of kidney transplantation. In high flux group, two people passed away, three people received a transplanted kidney, and one patient withdrew from further participation in the study $(n=44)$.

Data collection tool was a questionnaire with two parts. The first part was about to patients' demographic variables (age, gender, marital status, education, history of hemodialysis, vascular access, residence, and employment status). The second part was the "kidney disease quality of life-short form in hemodialysis patients" (KDQOL-SF). The questionnaire was translated into Persian by Pakpour et al (31). The questionnaire consisted of both general and specific dimensions. The specific dimension comprised 11 areas of health-related physical performance symptoms and problems (12 items), disease-associated limitations effects of kidney disease (8 items), imposed conditions, burden of kidney disease (4 items), employment work status (2 items), cognitive function (3 items), quality of social interactions (3 items), sexual functioning (2 items), sleep (4 items), social support (2 items), dialysis staff encouragement by dialysis personnel ( 2 items), and care satisfaction patients satisfaction rating (1 item). The general part of the questionnaire was about general health (SF-36) including eight domains of physical functioning (10 items), role physical (4 items), bodily physical pains (2 items), general health (6 items), vitality energy/fatigue (4 items), social function status (2 items), mental health (5 items) and role emotional (3 items) (32).

The domains were calculated independently according to the instructions on the analysis of questionnaire, and also average scores of the questions related to each area of life quality. Scores were from zero (worst) to 100 (best) quality of life. The reliability and validity of the questionnaire were assessed in Iran by Mortazavi et al (33).

In all phases, the devices were set for all patients so that the blood flow pump was regulated as $237 \pm 13 \mathrm{~mL} / \mathrm{min}$, dialysis solution flux was $500 \mathrm{~mL} / \mathrm{min}$ and bicarbonate solution was used at $37^{\circ} \mathrm{C}$, while blood flow was constant during the study. First, the purpose of study was explained followed by obtaining informed consents. Before the intervention, both the control and experimental groups filled the demographic and quality of life questionnaires. Afterwards, the experimental groups were undergone dialysis three times per week with high flux dialyzers (FR50, made by the Soha Co., Iran) and the control group was on a routine dialysis using low flux dialyzers (FR5, made by Soha Co., Iran) both for 6 weeks.

\section{Ethical issues}

The research followed the tenets of the Declaration of Helsinki. Informed consents were obtained from all patients. This study was conducted as the master degree dissertation in nursing which approved by ethics committee of research of Hamadan University of medical sciences (ethical code\# P.16.35.9.6168) and registered at the Iranian Registry of Clinical Trials (identifier: IRCT201506099014N68; http://www.irct.ir/trial/9507).

\section{Statistical analysis}

The collected data were analyzed by SPSS 16 software and using descriptive (mean, standard deviation, absolute and relative frequency distribution), and inferential statistics (paired $t$ test and Wilcoxon test). Additionally, $P$ values of less than 0.05 were considered statistically significant.

\section{Results}

Data showed that most of the participants in both groups were male $(56.8 \%)$, have more than 60 years old $(40.9 \%)$ and married (84.1\%). Most of them were illiterate in both low flux $(34.7 \%)$ and high flux $(38.6 \%)$ groups. The two groups were similar in terms of gender, age, marital status, and education (Table 1).

The effects of high flux dialyzer on the quality of life dimensions showed significant differences before and after the intervention in general health $(P<0.001)$, mental health $(P<0.001)$, symptoms and problems $(P<0.05)$, effects of kidney disease $(P<0.001)$, social support $(P<0.05)$ and physical functioning $(P<0.001)$. No significant differences were observed between before and after intervention in the scores of cognitive function and quality of social interactions, bodily pains, emotional role, physical role, work status, sexual function, and sleep $(P>0.05)$. However, the social function $(P<0.05)$ and patients satisfaction score were higher before the intervention in comparison with after intervention $(P<0.001)$ (Tables 2 and 3$)$.

Data analysis revealed no significant differences in the scores of the low flux dialyzer patients before and after the intervention of physical, mental health, body aches, 
Table 1. Comparison of demographic characteristics of patients in the two groups

\begin{tabular}{|c|c|c|c|c|c|c|}
\hline \multirow{3}{*}{\multicolumn{2}{|c|}{ Demographic characteristics }} & \multicolumn{4}{|c|}{ Group } & \multirow{3}{*}{ Statistical tests } \\
\hline & & \multicolumn{2}{|c|}{ Low flux dialyzer ( $n=44)$} & \multicolumn{2}{|c|}{ High flux dialyzer ( $n=44)$} & \\
\hline & & No. & $\%$ & No. & $\%$ & \\
\hline \multirow{2}{*}{ Gender } & Male & 27 & 55.1 & 25 & 56.8 & \multirow{2}{*}{$\chi 2=0.28, P=0.868$} \\
\hline & Female & 22 & 44.9 & 19 & 43.2 & \\
\hline \multirow{5}{*}{ Age (y) } & $30 \leq$ & 7 & 14.3 & 4 & 9.1 & \multirow{5}{*}{$\chi 2=4.389, P=0.701$} \\
\hline & $31-40$ & 5 & 10.2 & 6 & 13.6 & \\
\hline & $41-50$ & 6 & 12.2 & 4 & 9.1 & \\
\hline & $51-60$ & 9 & 18.4 & 12 & 27.3 & \\
\hline & $\geq 61$ & 22 & 44.9 & 18 & 40.9 & \\
\hline \multirow{4}{*}{ Marital status } & Single & 10 & 20.4 & 3 & 6.8 & \multirow{4}{*}{$\chi 2=5.379, P=0.012$} \\
\hline & Married & 31 & 63.3 & 37 & 84.1 & \\
\hline & Divorced & 2 & 4.1 & 1 & 2.3 & \\
\hline & Widowed & 6 & 12.2 & 3 & 6.8 & \\
\hline \multirow{5}{*}{ Education } & Illiterate & 17 & 34.7 & 17 & 38.6 & \multirow{5}{*}{$\chi 2=3.186, P=0.542$} \\
\hline & Reading and writing & 12 & 24.5 & 10 & 22.7 & \\
\hline & Under Diploma & 10 & 20.4 & 4 & 9.1 & \\
\hline & Diploma & 5 & 10.2 & 8 & 18.2 & \\
\hline & Academic & 5 & 10.2 & 5 & 11.4 & \\
\hline
\end{tabular}

emotional role, physical role, symptoms and problems, effects of kidney disease, job status, sexual function, sleep, social support, cognitive function, and quality of social interactions $(P>0.05)$. Significant differences occurred between before and after intervention in the scores of patients' satisfaction $(P<0.001)$ (Tables 4 and 5 ).

The overall mean quality of life in low flux and high flux groups before the intervention disclosed no significant differences between the two groups. Yet, it was observed that the overall mean score for the quality of life in the high flux group was significantly higher than the low flux group after the intervention $(P<0.001)$ (Table 6$)$.

\section{Discussion}

Some studies have shown that the quality of life is one of the most consistent and powerful predictors of mortality and hospitalization in hemodialysis patients (34). The results of this study showed a significantly higher quality of life in patients with high flux dialyzers than those treated with low flux dialyzers. In this regard, Kantartzi et al compared the quality of life in hemodialysis patients with low flux and high flux dialyzers and showed that the quality of

Table 2. Mean and SD scores for general and specific areas of quality of life in the high flux dialyzer group by paired $t$ test

\begin{tabular}{|c|c|c|c|c|}
\hline Quality of life & Times & Mean \pm SD & $T^{*}$ & $\boldsymbol{P}$ \\
\hline \multirow{2}{*}{ General health } & Before intervention & $40.79 \pm 18.79$ & \multirow{2}{*}{-3.806} & \multirow[t]{2}{*}{0.001} \\
\hline & After intervention & $48.75 \pm 14.86$ & & \\
\hline \multirow{2}{*}{ Physical functioning } & Before intervention & $41.93 \pm 29.43$ & \multirow{2}{*}{-4.885} & \multirow{2}{*}{0.001} \\
\hline & After intervention & $58.40 \pm 25.64$ & & \\
\hline \multirow{2}{*}{ Mental health } & Before intervention & $48.98 \pm 17.01$ & \multirow{2}{*}{-3.729} & \multirow{2}{*}{0.001} \\
\hline & After intervention & $56.76 \pm 13.79$ & & \\
\hline \multirow{2}{*}{ Body aches } & Before intervention & $55.56 \pm 24.51$ & \multirow{2}{*}{-1.753} & \multirow{2}{*}{0.087} \\
\hline & After intervention & $63.06 \pm 22.63$ & & \\
\hline \multirow{2}{*}{ Social function } & Before intervention & $73.86 \pm 17.01$ & \multirow{2}{*}{2.273} & \multirow{2}{*}{0.028} \\
\hline & After intervention & $67.04 \pm 19.45$ & & \\
\hline \multirow{2}{*}{ Symptoms and problems } & Before intervention & $64.63 \pm 21.57$ & \multirow{2}{*}{-2.635} & \multirow{2}{*}{0.012} \\
\hline & After intervention & $72.49 \pm 19.25$ & & \\
\hline \multirow{2}{*}{ Effects of kidney disease } & Before intervention & $48.34 \pm 19.31$ & \multirow{2}{*}{-4.104} & \multirow{2}{*}{0.001} \\
\hline & After intervention & $56.50 \pm 15.35$ & & \\
\hline \multirow{2}{*}{ Sexual function } & Before intervention & $59.37 \pm 29.37$ & \multirow{2}{*}{-1.936} & \multirow{2}{*}{0.082} \\
\hline & After intervention & $62.50 \pm 24.42$ & & \\
\hline \multirow{2}{*}{ Sleep } & Before intervention & $59.09 \pm 22.15$ & \multirow{2}{*}{-1.243} & \multirow{2}{*}{0.221} \\
\hline & After intervention & $62.15 \pm 11.57$ & & \\
\hline \multirow{2}{*}{ Patients satisfaction rating } & Before intervention & $72.22 \pm 18.16$ & \multirow{2}{*}{5.288} & \multirow{2}{*}{0.001} \\
\hline & After intervention & $56.05 \pm 25.31$ & & \\
\hline \multirow{2}{*}{ Cognitive function and quality of social interactions } & Before intervention & $63.63 \pm 15.89$ & \multirow{2}{*}{140} & \multirow{2}{*}{0.889} \\
\hline & After intervention & $63.33 \pm 11.56$ & & \\
\hline
\end{tabular}

*Paired $t$ test. 
Oshvandi et al

Table 3. Mean and SD scores for general and specific areas of quality of life in the high flux dialyzer group by Wilcoxon test

\begin{tabular}{lllr}
\hline Quality of life areas & Times & Mean \pm SD & $\boldsymbol{Z}^{*}$ \\
\hline \multirow{2}{*}{ Emotional role } & Before intervention & $56.81 \pm 42.27$ & -0.031 \\
& After intervention & $56.81 \pm 41.56$ & 0.975 \\
Physical role & Before intervention & $42.04 \pm 38.29$ & -1.16 \\
& After intervention & $48.29 \pm 35.10$ & 0.264 \\
Work status & Before intervention & $31.81 \pm 32.51$ & -0.057 \\
& After intervention & $29.54 \pm 32.91$ & 0.564 \\
Social support & Before intervention & $75.37 \pm 23.97$ & -2.160 \\
\hline
\end{tabular}

*Wilcoxon test.

Table 4. Mean and SD scores for general and specific areas of quality of life in the low flux dialyzer group by paired $t$ test

\begin{tabular}{|c|c|c|c|c|}
\hline Quality of life & Times & Mean \pm SD & $T^{*}$ & $P$ \\
\hline \multirow{2}{*}{ General health } & Before intervention & $45.10 \pm 16.02$ & \multirow{2}{*}{2.083} & \multirow{2}{*}{0.043} \\
\hline & After intervention & $38.98 \pm 19.99$ & & \\
\hline \multirow{2}{*}{ Physical functioning } & Before intervention & $44.49 \pm 22.66$ & \multirow{2}{*}{-1.263} & \multirow{2}{*}{0.213} \\
\hline & After intervention & $49.80 \pm 24.19$ & & \\
\hline \multirow{2}{*}{ Mental health } & Before intervention & $47.03 \pm 15.26$ & \multirow{2}{*}{0.164} & \multirow{2}{*}{0.870} \\
\hline & After intervention & $46.67 \pm 16.09$ & & \\
\hline \multirow{2}{*}{ Body aches } & Before intervention & $39.69 \pm 26.78$ & \multirow{2}{*}{0.631} & \multirow{2}{*}{0.531} \\
\hline & After intervention & $37.19 \pm 27.12$ & & \\
\hline \multirow{2}{*}{ Social function } & Before intervention & $61.22 \pm 27.51$ & \multirow{2}{*}{1.211} & \multirow{2}{*}{0.232} \\
\hline & After intervention & $56.12 \pm 28.60$ & & \\
\hline \multirow{2}{*}{ Symptoms and problems } & Before intervention & $61.82 \pm 18.53$ & \multirow{2}{*}{1.414} & \multirow{2}{*}{0.164} \\
\hline & After intervention & $56.93 \pm 19.42$ & & \\
\hline \multirow{2}{*}{ Effects of kidney disease } & Before intervention & $46.20 \pm 14.33$ & \multirow{2}{*}{-1.060} & \multirow{2}{*}{0.294} \\
\hline & After intervention & $48.61 \pm 14.13$ & & \\
\hline \multirow{2}{*}{ Sexual function } & Before intervention & $55.68 \pm 32.77$ & \multirow{2}{*}{-1.387} & \multirow{2}{*}{0.224} \\
\hline & After intervention & $76.04 \pm 23.51$ & & \\
\hline \multirow{2}{*}{ Sleep } & Before intervention & $50.66 \pm 18.76$ & \multirow{2}{*}{-0.492} & \multirow{2}{*}{0.625} \\
\hline & After intervention & $51.63 \pm 13.36$ & & \\
\hline \multirow{2}{*}{ Patients satisfaction rating } & Before intervention & $63.55 \pm 21.15$ & \multirow{2}{*}{4.051} & \multirow{2}{*}{0.001} \\
\hline & After intervention & $49.32 \pm 22.24$ & & \\
\hline \multirow{2}{*}{ Cognitive function and quality of social interactions } & Before intervention & $48.71 \pm 17.15$ & \multirow{2}{*}{0.395} & \multirow{2}{*}{0.695} \\
\hline & After intervention & $47.62 \pm 18.00$ & & \\
\hline
\end{tabular}

*Paired $t$ test.

Table 5. Mean and SD scores for general and specific areas of quality of life in the low flux dialyzer group by Wilcoxon test

\begin{tabular}{|c|c|c|c|c|}
\hline Quality of life areas & Times & Mean \pm SD & $Z^{*}$ & $P$ \\
\hline \multirow{2}{*}{ Social support } & Before intervention & $60.66 \pm 21.19$ & \multirow{2}{*}{-2.827} & \multirow{2}{*}{0.66} \\
\hline & After intervention & $52.04 \pm 17.74$ & & \\
\hline \multirow{2}{*}{ Emotional role } & Before intervention & $38.10 \pm 35.35$ & \multirow{2}{*}{-1.306} & \multirow{2}{*}{0.19} \\
\hline & After intervention & $47.62 \pm 37.87$ & & \\
\hline \multirow{2}{*}{ Physical role } & Before intervention & $28.57 \pm 31.86$ & \multirow{2}{*}{0.189} & \multirow{2}{*}{0.85} \\
\hline & After intervention & $27.55 \pm 32.77$ & & \\
\hline \multirow{2}{*}{ Work status } & Before intervention & $27.55 \pm 28.97$ & \multirow{2}{*}{0.383} & \multirow{2}{*}{0.72} \\
\hline & After intervention & $29.56 \pm 30.47$ & & \\
\hline
\end{tabular}

*Wilcoxon test.

life in dialysis patients was significantly higher with high flux dialyzers compared to when they applied low flux dialyzers (35). On the other hand, a 3-year follow up study by Unruh et al demonstrated no significant differences in the quality of life of patients treated with high flux and low flux dialyzers (36). Additionally the results of the study by Kavyannejad et al showed no significant differences in the incidence and severity of complications (variations of blood pressure, nausea, vomiting, itching, headache, and fever and chills) of patients during hemodialysis with lowor high-flux dialyzers (37).

This discrepancy could possibly be due to a longer follow-up of their study, during which a number of intervening factors, including many occupational, 
Table 6. Comparison of total quality of life of low flux group with high flux group before and after intervention

\begin{tabular}{lcc}
\hline \multirow{2}{*}{ Dialyzer } & Before intervention & After intervention \\
\cline { 2 - 3 } & Mean \pm SD & Mean \pm SD \\
\hline High flux & $49.31 \pm 49.21$ & $54.62 \pm 10.40$ \\
Low flux & $44.78 \pm 44.97$ & $43.89 \pm 11.64$ \\
Statistical tests & $T=1.566, P=0.121$ & $T=-4.667, P=0.000$ \\
\hline
\end{tabular}

economic, and family conditions which could influence the domains of life quality.

Boudville et al appraised the impacts of two high flux dialyzers (FX60 and high flux 80) on inflammatory markers and quality of life scores in hemodialysis patients for three months. Results showed that the two dialyzers did not act differently on inflammatory factors, except that FX60 dialyzer raised the scores in social interaction and physical function, but in general could not change the quality of life for the patients (38). Both studies indicate that the type of dialyzers can affect the quality of life domains. Santoro et al evaluated the effects of high flux and low flux dialyzers on the mortality rates of patients with ESRD in Italy. After following up a total of 64 patients for 3 years, they found the mortality rates in patients with high flux dialyzers were significantly different from those with low flux dialyzers (39). As already mentioned, a direct correlation between the quality of life and mortality rates in such patients was seen (36). Oshvandi et al suggested the routine use of high flux dialyzers while it is accompanied by better dialysis adequacy than to low flux dialyzers (40). Accordingly, it can be concluded that the use of high flux dialyzers can also enhance patient's quality of life.

In the group who administered high flux dialyzers, the mean scores in the areas of general health, physical and mental health, physical functioning, symptoms and problems, effects of kidney disease and social support were greater after the intervention than pre-intervention levels. Thus, high flux dialyzers increased the scores in the above areas, as a result, it improved the quality of life score. Song et al showed that resistance exercise for 12 weeks could raise the quality of life scores in physical and mental health of hemodialysis patients (41), which is same as the results of this study about the effects of high flux dialyzers on this both areas. Ward et al compared hemodialysis with high flux hemofiltration and high flux dialyzers using a quality of life questionnaire and concluded that the two dialyzers revealed no differences in the quality of life for dialysis patients, but the physical field significantly improved using both dialyzers (42). Likewise, Abraham et al (28) measured the impact of consultation on the quality of life in 50 hemodialysis patients using the questionnaire World Health Organization Quality of Life (WHOQOL). The experimental group received a consultation for 3 months and by training about diet, exercise, lifestyle changes, and the importance of timely follow-up in receiving dialysis. The results showed rises in the scores on the emotional and physical areas of the intervention group compared to the control group (28), which is consistent with our study. Previously, Rahimi et al examined the impact of continuous care model on the quality of life on 38 hemodialysis patients in Iran, Hamadan. The results indicated that the intervention, boosted the quality of life scores in the areas of general health, physical functioning, physical role, emotional role, social functioning, and bodily pain in the general dimension of the questionnaire (43), which disagree with our findings regarding the ineffectiveness of high flux dialyzers on the pain and social function areas, but are consistent in all other general areas. A longer follow-up care in the study of Rahimi et al could affect the areas of pain and social interactions. Likewise, Al-Jumaih et al investigated the quality of life in dialysis patients and found that the domains of cognitive status, physical function, and emotional role scored lowest, while the areas of care satisfaction, social status, and encouragement by dialysis staff attained the highest scores (44). A probable reason for the difference may be related to the type of study. This is a descriptive study in which data were collected with no interventions. A study by Ghavidel et al assessed the impact of collaborative care model on the quality of life for 32 patients undergoing hemodialysis in Iran. The results showed that the intervention improved the quality of life for hemodialysis patients in the areas of physical role, general health, physical functioning, and mental status confirming our results on the impact of high flux dialyzers upon the quality of life dimensions (45).

The current study demonstrated that the area of care satisfaction scored a significantly higher pre-intervention average than that detected after the intervention in both high flux and low flux groups. In fact, the dialyzers used resulted in a lower care satisfaction, which could have arisen from the fact that dialyzers sometimes cause hemodynamic instability, hence, patients may not satisfied with their dialysis procedure owing to the instability.

There were no significant differences in the scores of other areas before and after the intervention in the group with low flux dialyzers. This finding implies that low flux dialyzers had no impacts on the patients' quality of life. As Unruh et al reported, the scores of patients' quality of life in low flux group revealed no statistical changes after 3 years (36), which endorses our results concerning the impact of low flux dialyzers on the patient's quality of life. Similar to this study, Unruh et al also applied the questionnaire KDQOL-SF. Because patient advocacy is one of the main nurses' roles (46), to perform this, they need to be informed about proper treatment which can cause a significant improvement in caring of patients (47), reduce patients' problems and anxiety (48) and increase their quality of life.

\section{Conclusion}

The use of high flux dialyzers can be a useful way to increase the quality of life of hemodialysis patients, 
improve clinical practice, make positive changes in the treatment, and provide hemodynamic stability in these patients. While various studies have shown that boosted quality of life is associated with reduced mortality and morbidity in hemodialysis patients and also considering the results of this study, we can administer high flux dialyzers for dialysis patients to achieve these goals.

\section{Limitations of the study}

Possible limitations of the research are the intolerance of high flux dialyzers by some patients, which was controlled through precise monitoring of the patients' vital symptoms during dialysis and, if necessary, the use of normal saline solution with doctors' discretions, and/or excluding the patient from the study.

\section{Acknowledgments}

The authors would like to acknowledge the research deputy of Hamadan University of Medical Sciences as well as the Mother and Child Care Research Center and all patients and staff of the hemodialysis center of Shaheed Beheshti Hospital who cooperated in this study.

\section{Authors' contribution}

$\mathrm{KO}$ was the principal investigators of the study. $\mathrm{KO}$ and FS participated in preparing the concept of design. KO, FS and MG revised the manuscript and critically evaluated the intellectual contents. All authors participated in preparing the final draft of the manuscript, revisited the manuscript, and critically evaluated the intellectual contents. All authors have read and approved the content of the manuscript and confirmed the accuracy or integrity of any part of the work.

\section{Conflicts of interest}

The authors report no conflicts of interest. The authors alone are responsible for the content and writing of this paper.

\section{Ethical considerations}

Ethical issues (including plagiarism, data fabrication, double publication) have been completely observed by the authors.

\section{Funding/Support}

This study was supported by Hamadan University of medical sciences (P.16.35.9.6168).

\section{References}

1. Longo D, Fauci A, Kasper D, Hauser S. Harrison's Principles of Internal Medicine. 18th ed. McGraw-Hill Professional; 2011.

2. Oshvandi K, Kavyannejad R, Borzuo SR, Gholyaf M. HighFlux and Low-Flux Membranes: Efficacy in Hemodialysis. Nurs Midwifery Stud. 2014;3:e21764.

3. Buemi M, Lacquaniti A, Bolignano D, Donato V, Fazio MR, Campo S, et al. Dialysis and the elderly: an underestimated problem. Kidney Blood Press Res. 2008;31:330-6. doi: $10.1159 / 000164277$.
4. Ortiz A, Covic A, Fliser D, Fouque D, Goldsmith D, Kanbay $\mathrm{M}$, et al. Epidemiology, contributors to, and clinical trials of mortality risk in chronic kidney failure. Lancet. 2014;383:183143. doi: 10.1016/S0140-6736(14)60384-6.

5. Bayoumi M, Al Harbi A, Al Suwaida A, Al Ghonaim M, Al Wakeel J, Mishkiry A. Predictors of quality of life in hemodialysis patients. Saudi J Kidney Dis Transpl. 2013;24:254.

6. Kistler BM, Fitschen PJ, Ikizler TA, Wilund KR. Rethinking the restriction on nutrition during hemodialysis treatment. J Ren Nutr. 2015;25:81-7. doi: 10.1053/j.jrn.2014.08.008.

7. Kaviannezhad R, Oshvandi K, Borzuo R, Gholyaf M. Dialysis adequacy of low-flux membrane in hemodialysis patients. J Mazandaran Univ Med Sci. 2016;26:170-4. [Persian].

8. Naji A, Naroie S, Abdeyazdan G, Dadkani E. Effect of applying self-care orem model on quality of life in the patient under hemodialysis. Zahedan J Res Med Sci. 2012;14:8-12. [Persian].

9. Kara B, Açikel CH. The effect of intradialytic food intake on the urea reduction ratio and single-pool $\mathrm{Kt} / \mathrm{V}$ values in patients followed-up at a hemodialysis center. Turk J Med Sci. 2010;40:91-7. doi:10.3906/sag-0811-9

10. Sreejitha N, Devi K, Deepa M, Narayana G, Anil M, Rajesh $\mathrm{R}$, et al. The quality of life of patients on maintenance hemodialysis and those who underwent renal transplantation. Amrita J Med. 2012;8:1-44.

11. Zolfaghari M, Asgari P, Bahramnezhad F, AhmadiRad S, Haghani H. Comparison of two educational methods (familycentered and patient-centered) on hemodialysis: Related complications. Iran J Nurs Midwifery Res. 2015;20:87-92.

12. Singh RG, Singh S, Rathore SS, Choudhary TA. Spectrum of intradialytic complications during hemodialysis and its management: a single-center experience. Saudi J Kidney Dis Transpl. 2015;26(1):168.

13. Shahdadi H, Haghighi MJ, Sharafi E, Moghadam MP, Balouchi A, Bandadni E. Efficiency of High Blood Flow in Increasing Dialysis Efficacy versus Dialysis Complications. Indian J Public Health. 2017;8:256-60. doi: 10.5958/09765506.2017.00051.1.

14. Dukkipati R, Kalantar-Zadeh K, Kopple JD. Is there a role for intradialytic parenteral nutrition? A review of the evidence. Am J Kidney Dis. 2010;55:352-64. doi: 10.1053/j. ajkd.2009.08.006.

15. Dekker MJ, Marcelli D, Canaud BJ, Carioni P, Wang Y, Grassmann A, et al. Impact of fluid status and inflammation and their interaction on survival: a study in an international hemodialysis patient cohort. Kidney Int. 2017;91:1214-23. doi: 10.1016/j.kint.2016.12.008.

16. Munshi R, Ahmad S. Comparison of urea clearance in low efficiency low flux vs. high efficiency high-flux dialyzer membrane with reduced blood and dialysate flow: An in vitro analysis. Hemodial Int. 2014;18:172-4. doi: 10.1111/hdi.12054.

17. Schneider A, Drechsler C, Krane V, Krieter DH, Scharnagl H, Schneider MP, et al. The effect of high-flux hemodialysis on hemoglobin concentrations in patients with CKD: results of the MINOXIS study. Clin J Am Soc Nephrol. 2012;7:52-9. doi: 10.1371/journal.pone.0128079.

18. Ayli M, Ayli D, Azak A, Yüksel C, Atilgan G, Dede F, et al. The effect of high-flux hemodialysis on dialysis-associated amyloidosis. Ren Fail. 2005;27:31-4.

19. Mostovaya IM, Bots ML, van den Dorpel MA, Grooteman MP, Kamp O, Levesque R, et al. A randomized trial of hemodiafiltration and change in cardiovascular parameters. Clin J Am Soc Nephrol. 2014;9:520-6. doi: 10.2215/ CJN.07140713.

20. Tattersall J, Martin-Malo A, Pedrini L, Basci A, Canaud B, 
Fouque D, et al. EBPG guideline on dialysis strategies. Nephrol Dial Transplant. 2007;22:ii5-ii21. doi: 10.1093/ndt/gfm022.

21. Kavyannezhad R, Oshvandi K, Borzuo R, Gholyaf M. Comparison of two membrane low and high flux on the uptake of electrolytes, urea and creatinine in hemodialysis patients. Arak Med Univ J. 2016;18:59-66. [Persian].

22. Henrich WL. Principles and Practice of Dialysis. Lippincott Williams \& Wilkins; 2012.

23. Locatelli F, Martin-Malo A, Hannedouche T, Loureiro A, Papadimitriou M, Wizemann V, et al. Effect of membrane permeability on survival of hemodialysis patients. J Am Soc Nephrol. 2009;20:645-54. doi: 10.1681/ASN.2008060590.

24. Tattersall J, Canaud B, Heimburger O, Pedrini L, Schneditz D, Van Biesen W, et al. High-flux or low-flux dialysis: a position statement following publication of the Membrane Permeability Outcome study. Nephrol Dial Transplant. 2009;25:1230-2. doi: 10.1093/ndt/gfp626.

25. Nadi E, Bashirian S, Khosravi M. Assessing of dialysis adequacy in patients under hemodialysis in dialysis department of Ekbatan Hospital in Hamadan. Avicenna J Clin Med. 2003;10:27-33.

26. Lee GK, Chronister J, Bishop M. The effects of psychosocial factors on quality of life among individuals with chronic pain. Rehabil Couns Bull. 2008;51:177-89. doi: $10.1177 / 0034355207311318$.

27. Shojaei F. Quality of life in patients with heart failure. Journal of Hayat. 2008;14:5-13.

28. Abraham S, Venu A, Ramachandran A, Chandran PM, Raman S. Assessment of quality of life in patients on hemodialysis and the impact of counseling. Saudi J Kidney Dis Transpl. 2012;23:953-7. doi: 10.4103/1319-2442.100875.

29. Wu F, Cui L, Gao X, Zhou H, Yang M, Pan J, et al. Quality of life in peritoneal and hemodialysis patients in China. Ren Fail. 2013;35:456-9. doi: 10.3109/0886022X.2013.766573.

30. Sabry A, Al Saran K, Alghareeb A, Molhem A. Central venous catheter-related bacteremia in chronic hemodialysis patients: Saudi Single Center Experience. Eur J Gen Pract. 2011;10:1-5. doi: 10.4172/2161-0959.1000105.

31. Pakpour AH, Yekaninejad M, Molsted S, Harrison AP, Hashemi F, Saffari M. Translation, cultural adaptation assessment, and both validity and reliability testing of the kidney disease quality of life-short form version 1.3 for use with Iranian patients. Nephrol. 2011;16:106-12. doi: 10.1111/j.1440-1797.2010.01389.x.

32. Hays R, Amin N, Bullinger M, Mapes D, Kamberg C, Kallich J, et al. Kidney Disease Quality of LIfe Short Form (KDQOL$\mathrm{SF}^{\mathrm{TM}}$ ), Version 1.2: A Manual for Use and Scoring (German Questionnaire, Germany); 1997.

33. Montazeri A, Goshtasebi A, Vahdaninia M, Gandek B. The Short Form Health Survey (SF-36): translation and validation study of the Iranian version. Qual Life Res. 2005; 14:875-82.

34. López Revuelta K, García López FJ, de Alvaro Moreno F, Alonso J. Perceived mental health at the start of dialysis as a predictor of morbidity and mortality in patients with end-stage renal disease (CALVIDIA Study). Nephrol Dial Transplant. 2004;19:2347-53. doi: 10.1093/ndt/gfh392.

35. Kantartzi K, Panagoutsos S, Mourvati E, Roumeliotis A, Leivaditis K, Devetzis V, et al. Can dialysis modality influence quality of life in chronic hemodialysis patients? Low-flux hemodialysis versus high-flux hemodiafiltration: a cross-over study. Ren Fail. 2013;35:216-21. doi: 10.3109/0886022X.2012.743858

36. Unruh M, Benz R, Greene T, Yan G, Beddhu S, Devita M, et al. Effects of hemodialysis dose and membrane flux on healthrelated quality of life in the HEMO Study. Kidney Int. 2004; 66:355-66. doi: 10.1111/j.1523-1755.2004.00738.x.

37. Kavyannejad R, Oshvandi K, Borzuo R, Gholyaf M. A comparison of the effects of two low- and high-flux dialyzers on the patient's comfort and hemodialysis Complications: A Randomized Clinical Trial. Qom Univ Med Sci J. 2015;9:11-9. [Persian].

38. Boudville N, Horner M, McEwan E, Lim WH, Mudge DW, Markus HE. Effect of FX dialysers on systemic inflammation and quality of life in chronic haemodialysis patients. Blood Purif. 2009;27:187-93. doi: 10.1159/000190786.

39. Santoro A, Mancini E, Bolzani R, Boggi R, Cagnoli L, Francioso $A$, et al. The effect of on-line high-flux hemofiltration versus low-flux hemodialysis on mortality in chronic kidney failure: a small randomized controlled trial. Am J Kidney Dis. 2008;52:507-18. doi: 10.1053/j.ajkd.2008.05.011.

40. Oshvandi K, Kavyannejad R, Borzuo R, Gholyaf M, Salavati M Dialysis adequacy with high flux membrane in hemodialysis patients at Shahid Beheshti hospital, Hamedan. J Urmia Nurs Midwifery Fac. 2012;10:1-8. [Persian].

41. Song W-J, Sohng K-Y. Effects of progressive resistance training on body composition, physical fitness and quality of life of patients on hemodialysis. J Korean Acad Nurs. 2012;42:94756. doi: $10.4040 / j k a n .2012 .42 .7 .947$.

42. Ward RA, Schmidt B, Hullin J, Hillebrand GF, Samtleben W A comparison of on-line hemodiafiltration and high-flux hemodialysis: a prospective clinical study. J Am Soc Nephrol. 2000;11:2344-50

43. Rahimi A, Ahmadi F, Gholyaf M. Effects of applying continuous care model on quality of life in hemodialysis patients. Razi Journal of Medical Sciences. 2006;13:123-34.

44. Al-Jumaih A, Al-Onazi K, Binsalih S, Hejaili F, Al-Sayyari A. A study of quality of life and its determinants among hemodialysis patients using the KDQOL-SF instrument in one center in Saudi Arabia. Arab J Nephrol Transplant. 2011;4:125-30

45. Ghavidel F, Mohammadzadeh S, Pirasteh H, Alavi Majd H. Effect assessment of applying the partnership care model on quality of life in hemodialysis patients reffering to Be'sat Hospital of IRI Air Force. Ebnesina. 2009;12:22-27.

46. Oshvandi K, Hassan Shiri F, Safari M, Fazel MR, Salavati, $M$, Hassan Tehrani T. Effect of pre-warmed intravenous fluid therapy on prevention of postoperative shivering after caesarean section. Hayat. 2011;17:5-15. [Persian].

47. Oshvandi Kh, Keshmiri Kh, Salavati M, Emkanjoo Z, Musavi S. Effectiveness of education based on orem's self-care model in self-care activity of patients with implantable cardioverter defibrillators. Hayat. 2013;19:47-55. [Persian].

48. Sangestani G, Khatiban M, Pourolajal J, OshvandiKh. Influence of Doula on the Primiparous Parturients' Anxiety in the Delivery Ward. Hayat. 2013;19:48-60. [Persian].

Copyright (c) 2019 The Author(s); Published by Nickan Research Institute. This is an open-access article distributed under the terms of the Creative Commons Attribution License (http://creativecommons.org/licenses/by/4.0), which permits unrestricted use, distribution, and reproduction in any medium, provided the original work is properly cited. 